\title{
Analisis Budaya Organisasi dan Gaya Kepemimpinan pada Badan Penelitian dan Pengembangan Industri Kementerian Perindustrian
}

\section{Analysis of Organizational Culture and Leadership Style at the Industrial Research and Development Agency of the Ministry of Industry}

\author{
Indri Rizky Seventia \\ Departemen Manajemen, Fakultas Ekonomi dan Manajemen, IPB University, Dramaga, Bogor 16680 \\ e-mail: seventia2121@yahoo.com \\ Lindawati Kartika* \\ Departemen Manajemen, Fakultas Ekonomi dan Manajemen, IPB University, Dramaga, Bogor 16680 \\ e-mail: lindawati.kartika@gmail.com
}

\begin{abstract}
The function of organizational culture is to engage all components of the organization, determining identity, energy injections, motivators, and can be used as guidelines for members of the organization. Organizational Culture is one of the key successes of BPPI in the assessment of PMPRB. The purpose of this research is to answer: (1) How the realization and expected of organizational culture at BPPI Ministry of Industry? (2) How is the leadership style of BPPI leadership of the Ministry of Industry that is analyzed through the perception of leaders and employees by Using Management Skill Assessment Instrument (MSAI)? (3) How recommendations are given regarding managerial implications of organizational culture and leadership style that need to be improved Upgrade to BPPI. The Research results of the organization BPPI Ministry of Industry realization is more likely to dominate to Clan culture and hierarchy. While the expected culture of BPPI Ministry of Industry to be more likely to dominate to Clan culture and Adhocracy.
\end{abstract}

Keywords: Leadership Style, Managerial Skill, MSAI, OCAI, Organizational Culture.

\begin{abstract}
ABSTRAK
Budaya organisasi berfungsi sebagai pengikat seluruh komponen organisasi, menentukan identitas, suntikan energi, motivator, dan dapat dijadikan pedoman bagi anggota organisasi. Budaya Organisasi salah satu kunci sukses pada BPPI dalam penilaian PMPRB. Tujuan penelitian ini adalah untuk menjawab: (1) Bagaimana realisasi budaya organisasi dan budaya organisasi yang diharapkan pada BPPI Kementerian Perindustrian? (2) Bagaimana gaya kepemimpinan yang dimiliki pimpinan BPPI Kementerian Perindustrian yang dianalisis melalui persepsi pimpinan maupun karyawan dengan menggunakan Management Skill Assessment Instrument (MSAI)? (3) Bagaimana rekomendasi yang diberikan terkait implikasi manajerial budaya organisasi dan gaya kepemimpinan yang perlu di perbaiki atau di tingkatkan pada BPPI. Hasil penelitian realisasi budaya organisasi BPPI Kementerian Perindustrian cenderung mengarah kepada budaya Klan dan Hirarki, sedangkan budaya organisasi yang diharapkan BPPI Kementerian Perindustrian cenderung mengarah kepada budaya Klan dan Adhokrasi.
\end{abstract}

Kata kunci: Budaya Organisasi, Gaya Kepemimpinan, Kemampuan Manajerial, MSAI, OCAI.

*Corresponding author 


\section{PENDAHULUAN}

Reformasi Birokrasi ditujukan mewujudkan peningkatan pelayanan kepada masyarakat di lingkungan Kementerian/Lembaga (K/L) Negara dan Pemerintah Daerah. Sesuai dengan Peraturan Presiden Nomor 81 tahun 2010 tentang Grand Design Reformasi Birokrasi 2010-2015 sebagai landasan hukum reformasi birokrasi, yang di tindak lanjuti oleh KemenPAN-RB. Menindaklanjuti Peraturan PerMenPAN \& RB tersebut, Kementerian Perindustrian membentuk Tim RB di lingkungan Kementerian Perindustrian, Inspektorat Jendral diamanatkan untuk melaksanakan Monitoring dan Evaluasi. Banyaknya perubahan yang terjadi disetiap area, perlu dilakukan manajemen perubahan. Pada penilaian PMPRB Kementerian Perindustrian mengalami perbedaan dapat dilihat pada Gambar 1.

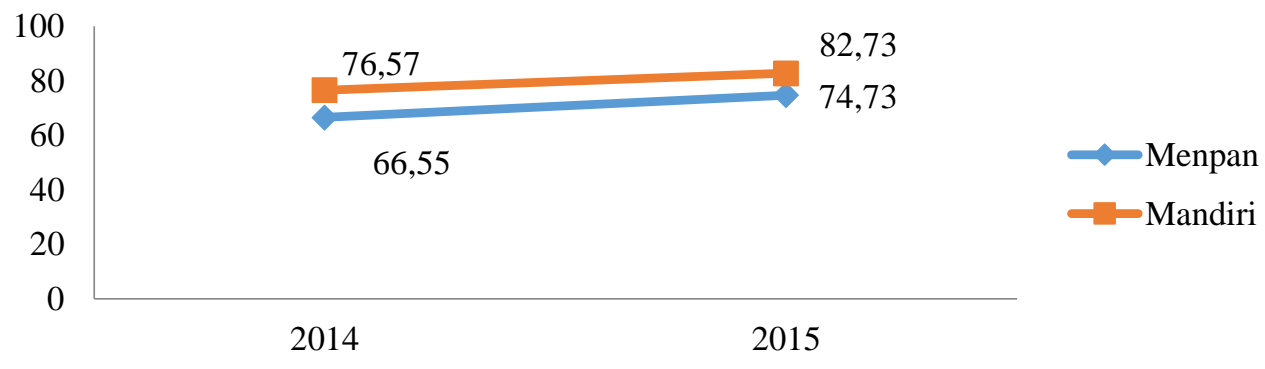

Gambar 1. Grafik PMPRB (Penilaian Mandiri Pelaksanaan Reformasi Birokrasi) pada Kementerian Perindustrian Tahun 2014-2015

Berdasarkan Gambar 1, dapat dilihat bahwa penilaian PMPRB Kementerian Perindustrian terus mengalami kenaikan dari tahun 2014 sampai dengan tahun 2015, akan tetapi memiliki perbedaan penilaian dan evaluasi yang signifikan terhadap Menpan. Penilaian yang dilakukan tersebut juga memberikan gambaran terhadap unit kerja lainnya yang masih terdapat pada kementerian perindustrian. Sebagai unit kerja Penelitian dan Pengembangan Industri, BPPI tentu memiliki peran yang penting dalam memajukan perindustrian karena peningkatan industri sebagian besar berasal dari hasil inovasi yang dilakukan oleh BPPI, namun BPPI juga tidak luput dari perubahan karena era reformasi birokrasi pada saat ini. Perubahan pada BPPI ini terlihat dari peran BPPI yang semula bersifat watchdog menjadi in house consultant.

Apabila dilihat dari kedudukannya BPPI ini merupakan salah satu lembaga pemerintah yang memiliki tugas dalam menentukan perkembangan perindustrian di Indonesia, peran ini merupakan salah satu peran yang penting dalam suatu negara, karena hal tersebut merupakan salah satu ujung tombak dari perokonomian nasional.Salah satu upaya yang dilakukan Kementerian Perindustrian mengatasi hal tersebut adalah melalui manajemen perubahan, salah satunya melalui Budaya Organisasi dan Gaya Kepemimpinan yang efektif dalam melaksanakan reformasi birokrasi. Salah satu kegagalan dalam pengelolahan organisasi pada lembaga pemerintahan adalah lemahnya pemimpin dalam menjalankan tugas yang diemban. Hal ini disebabkan oleh kurangnya peran seorang pemimpin dalam menentukan kebijakan yang diambil atau gaya kepemimpinannya tidak ideal dan juga kurang memahami kondisi mental dan fisik pegawai (Setiawan, 2010).

Akibat terjadinya interaksi dengan karakteristik masing-masing serta banyak kepentingan yang membentuk gaya hidup, pola perilaku, dan etika kerja, yang semuanya akan mencirikan kondisi suatu organisasi / budaya organisasi, sehingga setiap individu dalam organisasi tidak terlepas dari hakekat nilai-nilai budaya yang dianutnya yang akhirnya akan bersinergi dengan perangkat organisasi, teknologi, sistem, dan gaya kepemimpinan (Kurniawan, 2012).

Pelaksanaan reformasi birokrasi ditujukan untuk melakukan perubahan dan perbaikan pada delapan dimensi, yaitu organisasi, tatalaksana, peraturan perundang-undangan, sumber daya manusia aparatur, pengawasan, akuntabilitas, pelayanan publik, pola pikir (mind set) dan budaya kerja (cultural set) aparatur, untuk mencapai tujuan organisasi, manajemen dituntut handal untuk mengelola manajemen perubahan, tidak hanya menjaga agar organisasi tetap stabil, namun harus bisa membuat unggul dengan organisasi pesaing. Berdasarkan pemaparan tersebut, tujuan 
penelitian ini ialah (1) Menganalisis realisasi budaya organisasi dan budaya organisasi yang diharapkan pada BPPI Kementerian Perindustrian. (2) Menganalisis gaya kepemimpinan yang dimiliki pimpinan BPPI Kementerian Perindustrian baik melalui persepsi pimpinan maupun karyawan dengan menggunakan Management Skill Assessment Instrument (MSAI). (3) Memberikan rekomendasi implikasi manajerial budaya organisasi dengan gaya kepemimpinan yang perlu diperbaiki atau ditingkatkan pada BPPI Kementerian Perindustrian.

\section{METODE PENELITIAN}

Evaluasi Penilaian PMPRB (Penilaian Mandiri Pelaksanaan Reformasi Birokrasi) di Kementerian Perindustrian terus mengalami kenaikan dari tahun 2014 sampai dengan tahun 2015, akan tetapi memiliki perbedaan penilaian dan evaluasi yang signifikan terhadap Menpan. Salah satu upaya yang dilakukan oleh Kementerian Perindustrian adalah melalui manajemen perubahan, yang diimplementasikan pada budaya organisasi dan gaya kepemimpinan, seperti pada Badan Pengembangan Industri pada Kementerian Perindustrian. Evaluasi terkait pengimplementasian budaya organisasi dan gaya kepemimpinan menggunakan metode Organizational Culture Assessment Instrument (OCAI) dari Cameron dan Quinn (2006). Budaya organisasi digambarkan dengan apa yang disebut dengan nilai, gaya kepemimpinan yang dominan, bahasa dan sumber, prosedur dan rutinitas, dan definisi kesuksesan yang membuat organisasi bersifat unik Cameron dan Quinn (2006). Lebih lanjut, budaya organisasi juga dianalisis melalui (Six Key Deminsion of Culture) yang membagi menjadi Klan, Hirarki, Adhokrasi, dan Market, sedangkan gaya kepemimpinan dianalisis menggunakan metode Management Skill Assessment Instrument (MSAI) dan melihat kemampuan manajerial dengan membagi gaya kepemimpinan menjadi empat tipe, antara lain: Klan, Hirarki, Adhokrasi, atau Market, dimana nantinya gaya kepemimpinan dalam organisasi tersebut akan mempengaruhi budaya organisasi. Analisis jenis budaya organisasi dan gaya kepemimpinan pada penelitian ini, dapat berimplikasi dan berguna sebagai saran bagi kementerian perindustrian. Pemikiran pada penelitian ini dapat divisualisasikan pada Gambar 2.

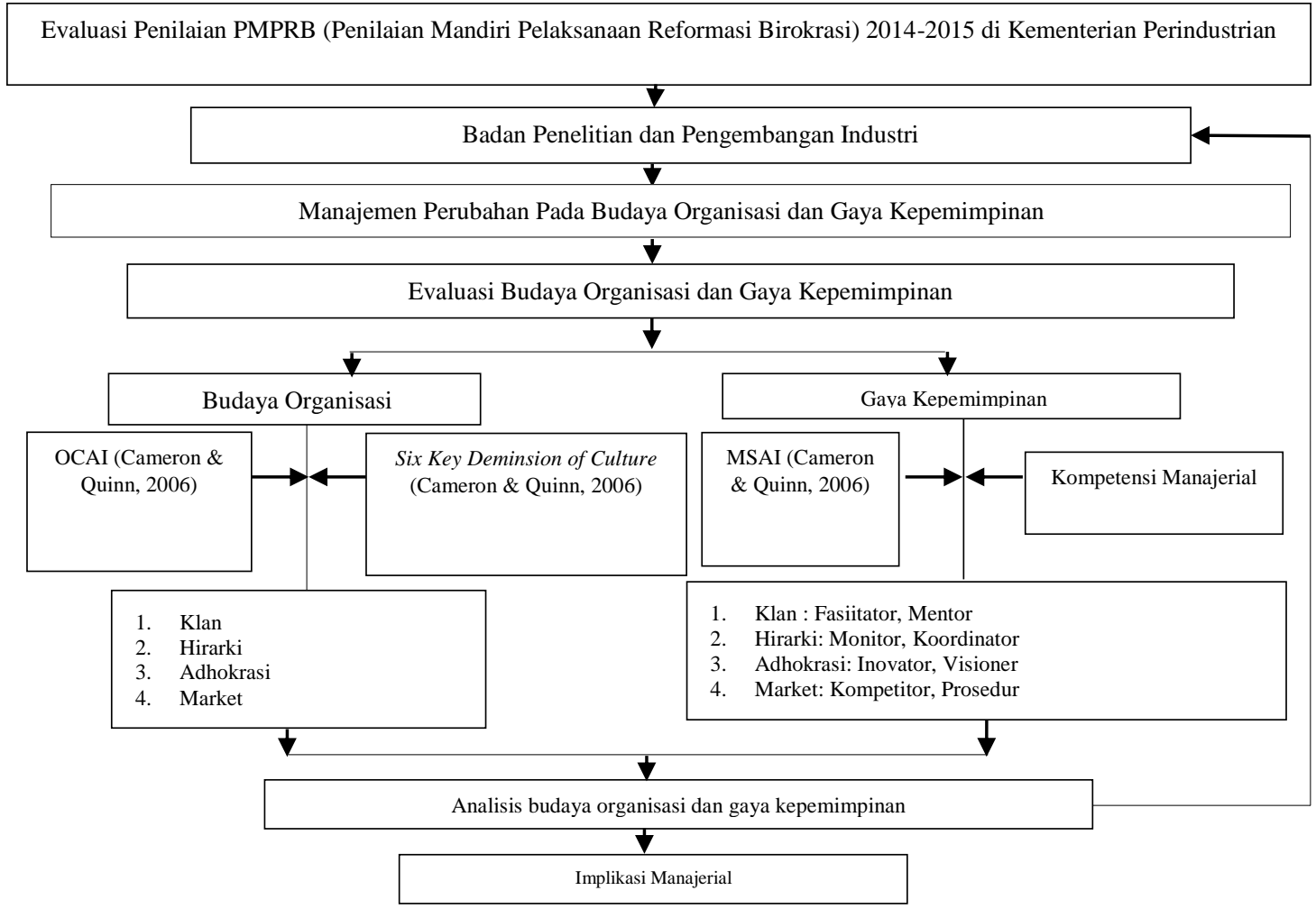

Gambar 2. Kerangka pemikiran penelitian 


\section{HASIL DAN PEMBAHASAN}

\section{Implikasi Perbandingan hasil Analisis Budaya Organisasi pada BPPI Kementerian Perindustrian.}

Proses analisis berdasarkan kecenderungan budaya organisasi pada pada masing-masing dimensi budaya organisasi menggunakan instrumen Organizational Culture Assesment Instrument (OCAI), hal ini bertujuan untuk melihat kecenderungan dimensi dari budaya organisasi melalui perbedaan karakteristik tipe realisasi budaya organisasi dengan budaya organisasi yang diharapkan pada masing-masing dimensi budaya organisasi. Lebih jelasnya dimensi realisasi budaya organisasi pada BPPI Kementerian Perindustrian dapat dilihat pada Gambar 3 berikut.

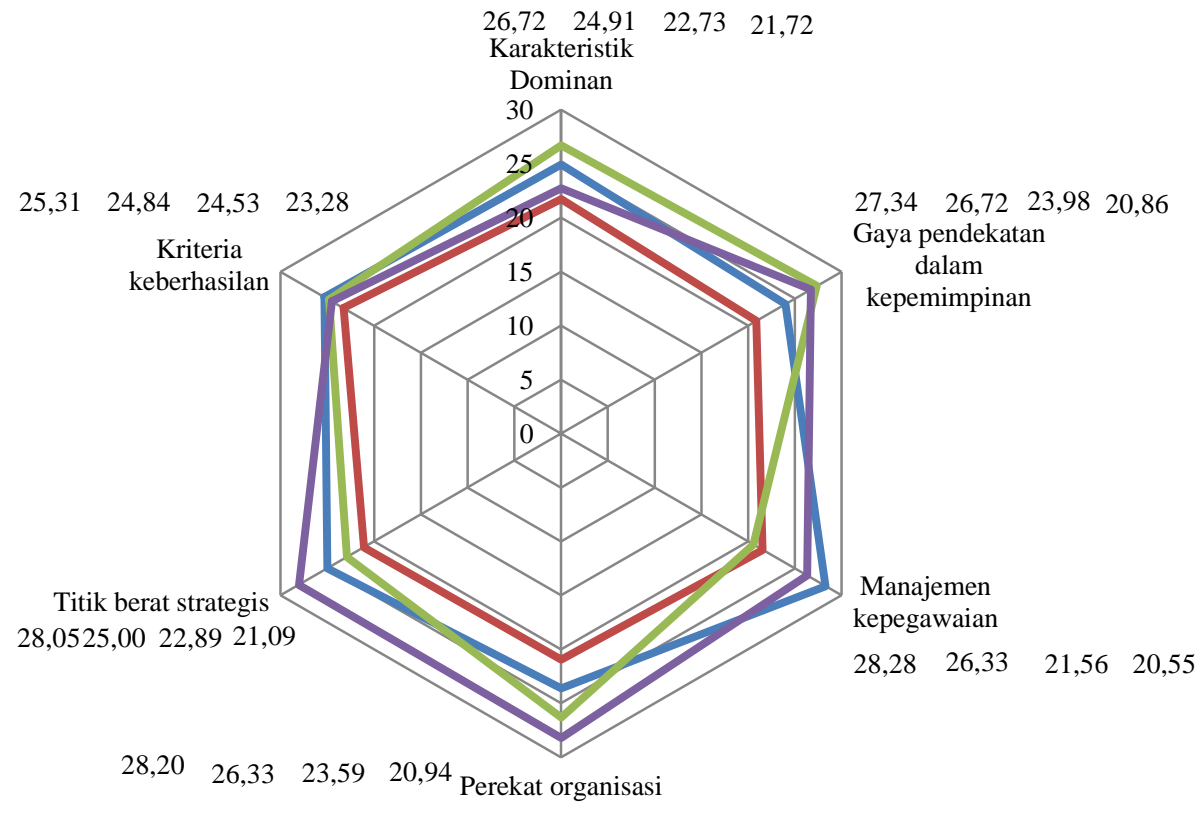

Jurnal Manajemen dan Organisasi (JMO),

Vol. 11 No. 2 , Al $115-124$
$27,34 \quad 26,72 \quad 23,98 \quad 20,86$

dalam

kepemimpinan

Manajemen

kepegawaia

$28,28 \quad 26,33 \quad 21,56 \quad 20,55$

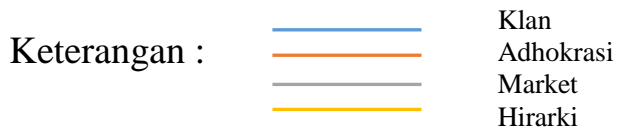

Gambar 3. Dimensi-dimensi Realisasi Budaya Organisasi pada BPPI Kementerian Perindustrian Sumber: Data diolah 2017

Berdasarkan Gambar 3, diketahui jika dimensi realisasi budaya organisasi yang berkembang pada karateristik dominan dan gaya pendekatan dalam kepemimpinan lebih cenderung ke tipe budaya market dengan nilai rata-rata sebesar 26,72 untuk karakteristik dominan dan 27,34 untuk gaya pendekatan dalam kepemimpinan, hal ini memberikan gambaran jika BPPI Kementerian Perindustrian memang memiliki keinginan untuk dapat memenangkan persaingan, karakteristik tersebut memang merupakan sesuatu yang positif melihat BPPI sebagai organisasi tumpuan Kementerian Perindustrian. Berbeda dengan karakteristik perekat organisasi dan titik berat strategis, karakteristik perekat organisasi dan titik berat strategis kecenderungan pada realisasi lebih mengarah kepada tipe budaya hirarki dengan nilai rata-rata sebesar 28,20 untuk perekat organisasi dan 28,05 untuk titik berat strategis. Upaya mempererat organisasi, pada saat ini dilakukan dengan berdasarkan kepada peraturan yang kaku dan ketat. Pada kriteria manajemen kepegawaian dan kriteria keberhasilan realisasi pada dimensi budaya lebih cenderung ke tipe budaya klan dengan nilai rata-rata 28,28 untuk manajemen kepegawaian dan 25,31 untuk kriteria keberhasilan. Hal ini memberikan gambaran jika manajemen kepegawaian pada saat ini lebih 
seperti keluarga besar serta keberhasilan juga tidak beroritasi kepada hasil tetapi lebih kepada proses yang telah dilalui.

Jika dilihat dari kondisi budaya organisasi yang diharapkan, dimensi-dimensi budaya organisasi pada BPPI Kementerian Perindustrian dapat dilihat pada Gambar 4 berikut.

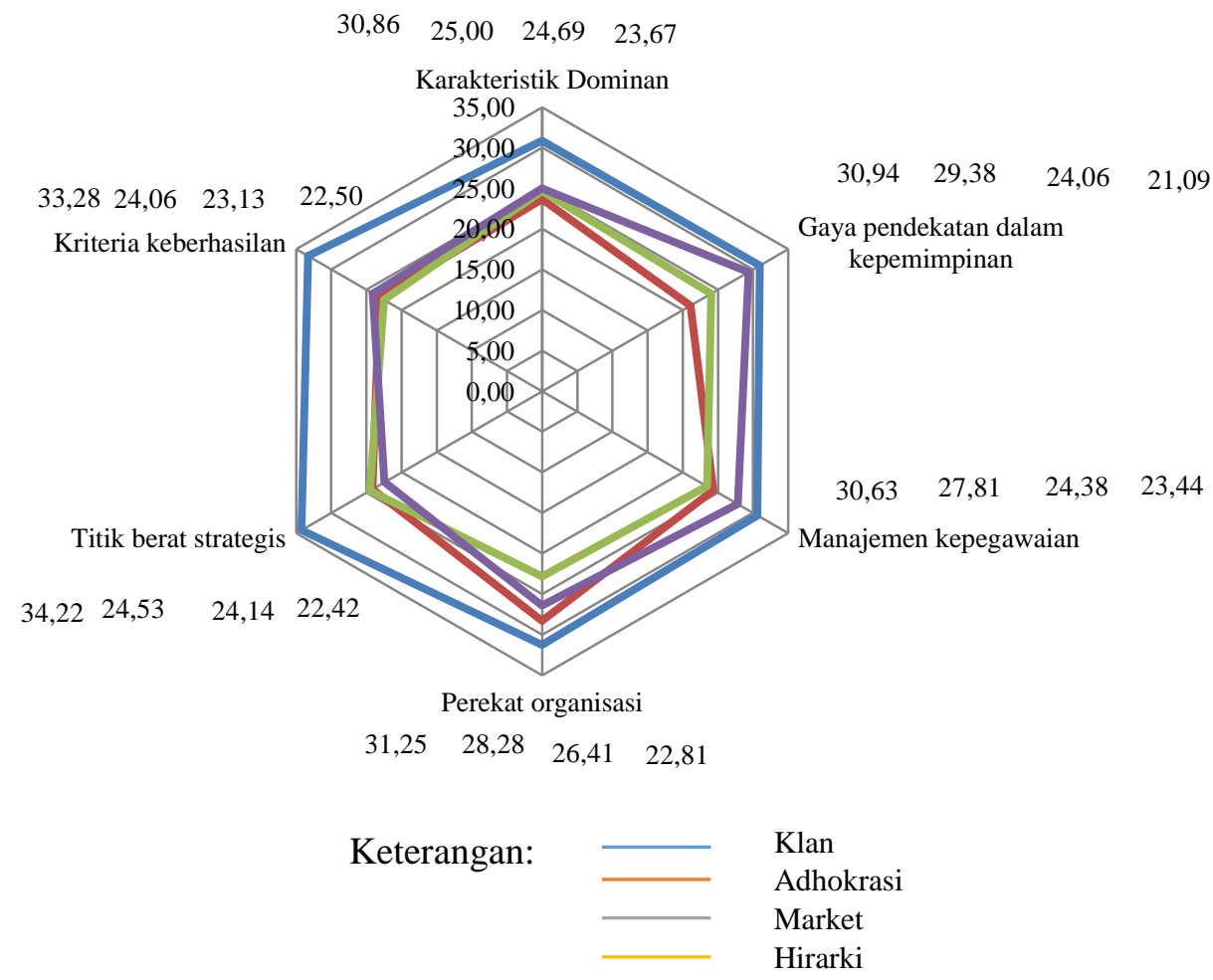

Gambar 4. Dimensi-dimensi Budaya Organisasi yang diharapkan pada BPPI Kementerian Perindustrian Sumber: Data diolah 2017

Berdasarkan Gambar 4, diketahui jika dimensi-dimensi budaya organisasi yang diharapkan pada BPPI Kementerian Perindustrian ini didominasi oleh tipe budaya klan. Dari hasil perhitungan rata-rata nilai dimensi organisasional seluruh dimensi mengharapkan lebih kearah budaya klan, dengan nilai rata-rata dimensi lebih dari 30, artinya dimensi-dimensi realisasi budaya berkembang dinilai tidak sesuai dengan karakteristik organisasi. Dimensi-dimensi budaya pada BPPI Kementerian Perindustrian lebih diharapkan memiliki nilai budaya tipe klan, karena pada tipe budaya ini karyawan merasa lebih dapat berkembang dan bekerja dengan lebih menyenangkan.

Melihat perbedaan realisasi budaya organisasi dan budaya organisasi yang diharapkan, secara keseluruhan pengujian lebih lanjut dilakukan dengan menguji perbedaan rata-rata menggunakan paired sampel $t$-test yang hasilnya disajikan dalam bentuk Tabel 1 berikut.

Tabel 1. Uji Perbedaan rata-rata Dimensi-dimensi realisasi Budaya Organisasi dengan Budaya yang diharapkan.

\begin{tabular}{lcccccc}
\hline Tipe Budaya & Realisasi & Harapan & Selisih & Ujit & Hasil & Keterangan \\
\hline Klan & 25,18 & 31,86 & 6,68 & $-6,220$ & 0,000 & Signifikan \\
\hline Adhokrasi & 21,58 & 24,11 & 2,53 & $-2,652$ & 0,009 & Signifikan \\
\hline Market & 24,78 & 23,67 & $-1,11$ & 0,939 & 0,350 & Tidak signifikan \\
\hline Hirarki & 26,09 & 25,85 & $-0,24$ & 0,271 & 0,787 & Tidak signifikan \\
\hline
\end{tabular}

Sumber: Data diolah 2017 
Ketentuan dalam menentukan paired sample t-test dapat dilihat dari perbandingan nilai signifikansi dengan nilai signifikan yang dipilih (Sugiyono, 2010). Jika dilihat dari hasil uji perbedaan rata-rata dimensi-dimensi realisasi budaya organisasi dengan budaya organisasi yang diharapkan menggunakan analisis paired sample t-test diketahui pada tipe budaya klan terdapat perbedaan yang signifikan antara realisasi budaya organisasi dengan budaya organisasi yang diharapkan. Hal ini dilihat dari $(\mathrm{t}=-6,220$ dan $\mathrm{p}=0,000<0,05)$.

Budaya organisasi Adhokrasi diketahui juga terdapat perbedaan yang signifikan antara tipe realisasi budaya organisasi dengan budaya organisasi yang diharapkan, hal ini dapat di lihat dari hasil uji $(\mathrm{t}=-2,652$ dan $\mathrm{p}=0,009<0,05)$. Sedangkan pada tipe budaya Market dan Hirarki keduanya tidak memiliki perbedaan signifikan antara realisasi budaya organisasi dengan budaya organisasi yang diharapkan.

Melihat visualisasi perbedaan secara keseluruhan realisasi budaya organisasi dengan budaya organisasi yang diharapkan dapat dilihat pada Gambar 5.

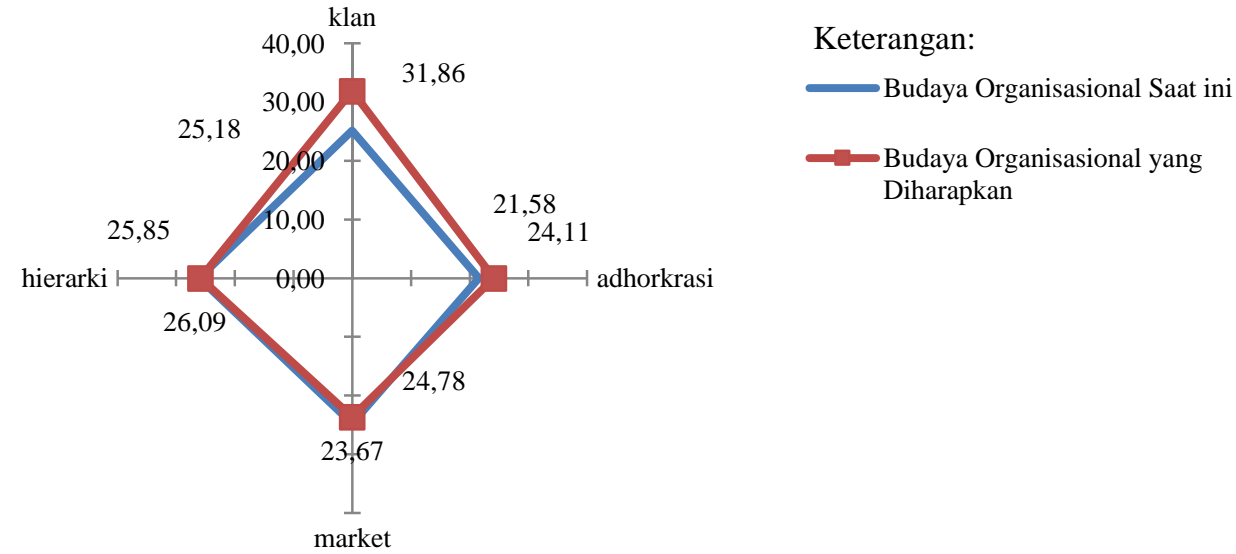

Gambar 5. Perbedaan Budaya Organisasi BPPI Antara realisasi dengan Diharapkan Secara Keseluruhan

Sumber: Data diolah 2017

Berdasarkan hasil pengujian tersebut, dapat dilihat bahwa tipe budaya klan dan adhokrasi yang banyak memiliki perbedaan signifikan antara realisasi budaya organisasi dengan budaya organisasi yang diharapkan. Tipe Budaya klan lebih menekankan keakraban dan ikatan emosional untuk saling berbagi layaknya sebagai keluarga besar, budaya ini juga mengutamakan adanya kerja sama dan partisipasi dari seluruh karyawan. Pimpinan pada budaya organisasi klan ini lebih berperan sebagai mentor dan pengarahan ketika karyawan merasa ragu atau kebingungan. Berbeda halnya dengan tipe budaya adhokrasi, tipe budaya ini dicirikan dengan nilai inovatif yang tinggi dari karyawan maupun pimpinan, sehingga suasana kerja yang terbangun lebih dinamis.

\section{Analisis Persepsi Pimpinan dan Persepsi Karyawan terhadap Kemampuan Manajerial Pimpinan pada BPPI Kementerian Perindustrian.}

Melihat kesesuaian antara budaya organisasi dengan kemampuan manajerial yang dimiliki oleh sumber daya manusia pada Badan Penelitian dan Pengembangan Industri Kementerian Perindustrian, maka dilakukan analisis terhadap kemampuan para pimpinan yang melibatkan pimpinan dengan karyawan dengan menggunakan instrumen Management Skill Assesment Instrument (MSAI). Hasil analisis yang telah dilakukan disajikan dalam pada Gambar 6. 


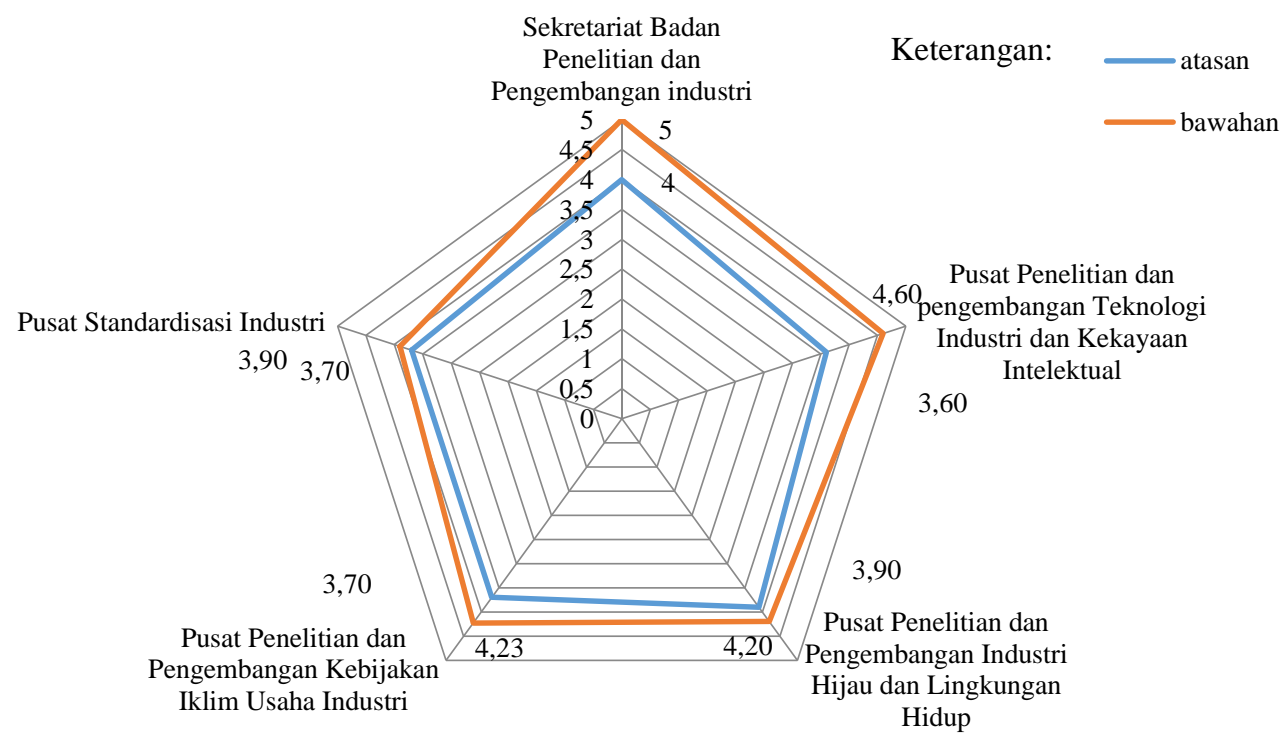

Gambar 6. Perbedaan Kemampuan Gaya Kepemimpinan Berdasarkan Persepsi Pimpinan dengan Persepsi Karyawan

Sumber: Data diolah 2017

Berdasarkan Gambar 6, dapat diketahui jika dari seluruh kemampuan manajerial sesuai dengan tipe budaya klan, adhokrasi, market dan hirarki seluruhnya memiliki selisih yang positif, artinya persepsi karyawan lebih tinggi dibandingkan persepsi pimpinan. Hal ini memberikan gambaran bahwa kemampuan manajerial yang dilakukan oleh pimpinan dinilai karyawan sudah baik.

Paired sampel t-test merupakan uji yang dilakukan untuk melihat perbedaan mana yang memiliki dampak nyata di kemampuan gaya kepemimpinan menurut persepsi pimpinan dan persepsi karyawan. Adapun hasil uji paired sampel t-test disajikan dalam bentuk Tabel 2 berikut.

Tabel 2. Kemampuan Manajerial Menurut Tipe dan Variabel Budaya

\begin{tabular}{lllllll}
\hline Variabel & Pimpinan & Karyawan & Selisih & Uji t & Hasil & Keterangan \\
\hline Klan & 50,63 & 56,90 & 6,27 & $-2,043$ & 0,045 & Signifikan \\
Adhokrasi & 48,69 & 55,13 & 6,44 & $-2,323$ & 0,024 & Signifikan \\
Market & 49,38 & 54,20 & 4,82 & $-1,950$ & 0,056 & Tidak Signifikan \\
Hirarki & 48,53 & 55,38 & 6,85 & $-2,278$ & 0,026 & Signifikan \\
\hline
\end{tabular}

Sumber: Data diolah 2017

Ketentuan dalam menentukan paired sample t-test dapat dilihat dari perbandingan nilai signifikansi dengan nilai signifikan yang dipilih (Sugiyono, 2010). Berdasarkan hasil uji perbedaan rata-rata kemampuan manajerial pada setiap tipe dan variabel budaya organisasi antara persepsi pimpinan dan karyawan dengan menggunakan Paired Sampel T-Test yang disajikan dalam Tabel 8 , diketahui jika kemampuan yang memiliki perbedaan signifikan antara persepsi pimpinan dengan karyawan pada budaya klan $(\mathrm{t}=-2,043$ dan $\mathrm{p}=0,045<0,05)$, budaya adhokrasi $(\mathrm{t}=-2,323$ dan $\mathrm{p}=0,024<0,05)$, dan budaya hirarki $(\mathrm{t}=-2,278$ dan $\mathrm{p}=0,026<0,05)$, namun kemampuan pada budaya market tidak signifikan antara persepsi pimpinan dengan karyawan $(\mathrm{t}$ $=-1,950$ dan $\mathrm{p}=0,056<0,05)$, maka tidak ada perbedaan persepsi antara karyawan dan pimpinan artinya persepsi kemampuannya sama.

Klan dan adhokrasi merupakan budaya yang diharapkan ditunjukan dengan warna putih, sedangkan gaya kepemimpinan yang harus diperbaiki pada BPPI ditunjukan melalui warna kuning, program yang tersedia pada BPPI ditunjukan pada warna hijau, dan Implikasi manajerial

Jurnal Manajemen dan Organisas JMO), 
yang disarankan untuk memperbaiki gaya kepemimpinan agar mencapai budaya organisasi yang diharapkan ditunjukan dengan warna biru. Hal tersebut dapat dilihat pada Gambar 7.

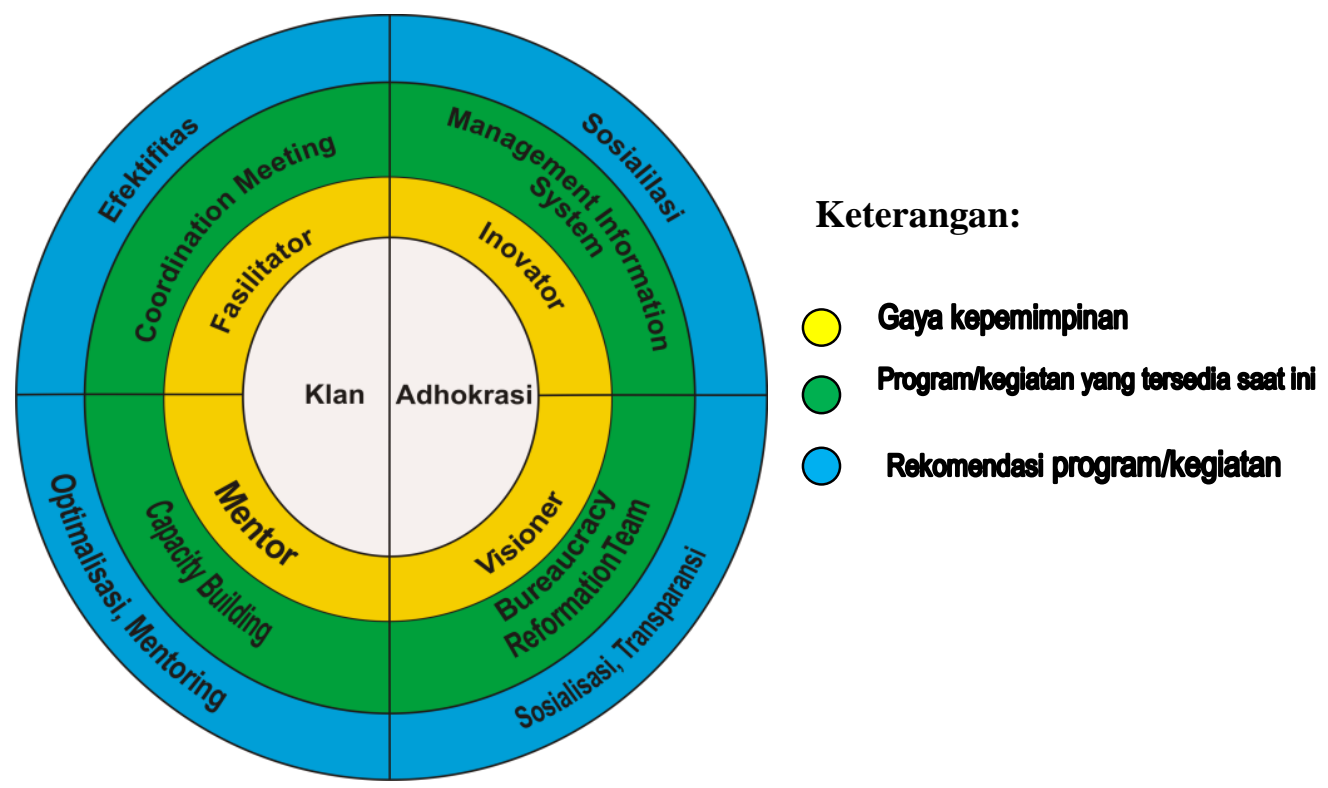

Gambar 7. Model Rekomendasi Perubahan Budaya Organisasi pada BPPI

Berdasarkan Gambar 7, demi tercapainya budaya Klan, peneliti merekomendasikan gaya kepemimpinan layaknya fasilitator dan mentor kegiatan yang sudah ada seperti rapat koordinasi (coordination meeting) dan capacity building baiknya ditingkatkan efektivitasnya dengan cara memperbaiki agenda kegiatan temu teknis kepegawaian yang dalam satu tahun hanya sekali menjadi lebih dari sekali dan hasil dari rapat kerja disampaikan kembali pada rapat internal unit, sedangkan untuk gaya kepemimpinan mentor, efektivitas dapat ditingkatkan melalui diklat teknis dan admnistratif sesuai dengan kemampuan pegawai, pengadaan memetakan jadwal diklat, teknis dan administratif pegawai sesuai kebutuhan dan pemimpin sebaiknya melakukan mentoring dan evaluasi kinerja pegawai.

Gaya kepemimpinan inovator, digunakan BPPI dalam menjalankan visi dan misinya guna melaksanakan perundang-undangan kementrian perindustrian dengan baik. Begitu pula dengan penambahan pembentukan balai atau unit baru sesuai dengan kemampuan inti daerah masingmasing. Akan tetapi, perlu adanya sosialisasi untuk mendukung kemajuan industri terutama bidang yang dapat mengakomodir kemampuan inti di daerah manapun. Terkait gaya kepemimpinan visioner, dalam rangka melaksanakan tugas pokok dan fungsinya, BPPI secara langsung memberi tanggapan mengenai program pemerintah dengan membentuk tim reformasi birokrasi dirasa sudah cukup baik. Namun, peneliti merekomendasikan adanya penyampaian progress report atas pengembangan pelaksanaan tupoksi dalam jangka waktu selama enam bulan.

Jika dihubungkan dengan karakteristik karyawan, sebagai upaya mempercepat ketercapaian pembentukan budaya klan maka ada beberapa karakteristik responden yang dapat mendukung hal tersebut. Jika dilihat pada karakteristik usia, budaya klan dan adhorkrasi ini tepatnya diterapkan pada karyawan yang memiliki usia 30-34 tahun, jika pada usia tersebut, sisi perkembangan psikologisnya sedang berada pada masa konsolidasi atau memperkuat dan dari kemampuan dinilai telah baik dengan adanya pengalaman kerja, artinya pada usia 30-34 keadaan seseorang sedang berada pada puncak produktif yang memiliki energi yang banyak serta telah mencapai kematang emosional sehingga besar kemungkinan mereka lebih fokus dalam melakukan sesuatu, termasuk dalam hal pekerjaan. Dilihat segi pendidikan, karakteristik yang dinilai paling baik untuk perkembangan tipe budaya klan dan adhokrasi adalah tingkat pendidikan 
Tipe budaya klan yang menitikberatkan kepada kerja sama tim dan tipe budaya adhokrasi yang cenderung inovatif memerlukan karakteristik karyawan yang secara teori lebih menguasai permasalahan pada dunia kerja, selain itu pada tipe budaya ini kerja sama merupakan unsur yang penting mengingat pekerjaan yang lebih dinamis dan memiliki pandangan jauh ke depan. Karakteristik masa kerja dinilai yang paling baik memiliki masa kerja 3-7 tahun, masa kerja ini pada umumnya sudah memiliki rasa kebersamaan diantara karyawan atau rasa loyalitas kepada organisasi karena sudah cukup lama mereka bekerja secara bersama sehingga jika diarahkan kepada nilai-nilai pada tipe budaya klan yang cenderung seperti keluarga besar dengan orientasi kerja sama yang baik akan lebih mudah dilakukan. Sama halnya dengan pengarahan yang dilakukan kepada nilai-nilai budaya adhokrasi yang cenderung inovasi dengan suasana kerja yang lebih dinamis akan lebih mudah dilakukan kepada karyawan yang telah memiliki pengalaman kerja. Karakteristik karyawan ini memang bukan suatu patokan yang pasti, namun pada umumnya keterhubungan tersebut dapat terjadi mengingat dalam sebuah organisasi terdapat perilaku dari individu yang dapat memberikan dampak terhadap kinerja karyawan.

\section{KESIMPULAN}

Berdasarkan hasil penelitian analisis budaya organisasi BPPI Kementerian Perindustrian dan gaya kepemimpinan dengan Management Skill Assessment Instrument (MSAI), maka dapat disimpulkan bahwa, Realisasi budaya organisasi BPPI Kementerian Perindustrian lebih cenderung mengarah kepada budaya Klan dan budaya Hirarki, sedangkan budaya yang diharapkan BPPI Kementerian Perindustrian yang diharapkan lebih cenderung mengarah kepada budaya Klan dan budaya Adhokrasi. Gaya kepemimpinan yang dimiliki pimpinan BPPI Kementerian Perindustrian baik melalui persepsi pimpinan maupun karyawan tidak menunjukkan kesenjangan. Hal ini menunjukkan bahwa, gaya kepemimpinan pada Badan Penelitian dan Pengembangan Industri Kementerian Perindustrian mengarah ke gaya kepemimpinan fasilitator, mentor, innovator dan visioner. Rekomendasi bagi Badan Penelitian dan Pengembangan Industri Kementerian Perindustrian budaya organisasi yang perlu ditingkatkan adalah budaya Klan dan Adhokrasi dengan meningkatkan Gaya kepemimpinan melalui efektivitas, sosialisasi, transparansi dan mentoring pada program yang telah berjalan.

\section{DAFTAR PUSTAKA}

Cameron, K. S., \& Quinn, R. E. (2006). Diagnosing and Changing Organizational Culture. San Francisco: Jossey-Bass.

Kurniawan, Y. (2012). Evaluasi budaya organisasional biro kepegawaian dan organisasi kementerian dan pariwisata menggunakan konsep organizational culture assessment instrument (OCAI). Yogyakarta: Universitas Gadjah Mada.

[KemenPAN-RB] Kementerian Pendayagunaan Aparatur Negara dan Reformasi Birokrasi. (2016). Relevansi dan Kontekstualisasi Strategi Reformasi Birokrasi 2015-2019 [internet]. [diunduh 2017 Feb 25]. Tersedia pada https://www.menpan.go.id/cerita-sukses-rb/5411relevansi-dan-kontekstualisasi-strategi-reformasi-birokrasi-2015-2019-1.

[Kemenperin] Kementerian Perindustrian. (2011). Solusi Reformasi Birokrasi dalam Kenyataan. $\left.\begin{array}{lllll}\text { [diunduh } & 2017 & \text { Feb } & 2\end{array}\right]$ Tersedia https://www.kemenperin.go.id/ind/about/file_upload/solusi-repormasi-birokrasi-dalamkenyataan.pdf.

[Kemenperin] Kementerian Perindustrian. (2014). Penilaian PMPRB 2014. [diunduh 2017 Feb 25]. Tersedia pada https://www.kemenperin.go.id/ind/about/file_upload/PenilaianPMPRB -2014.pdf

[Kemenperin] Kementerian Perindustrian. (2015). Penilaian PMPRB 2015. [diunduh pada 2017 Feb 25]. Tersedia https://www.kemenperin.go.id/ind/about/file_upload/PenilaianPMPRB -2015.pdf

pada Jurnal Manajemen dan Organisasi (JMO), Vol. 11 No. 2 , 
[Kemenperin] Kementerian Perindustrian. 2015. Profil Badan Penelitian dan Pengembangan Industri. [diunduh pada 2017 Mar 2]. Tersedia pada http://bppi.kemenperin.go.id/page/profil-badan-litbang-industri/.pdf.

Setiawan, Y. (2010). Pengaruh gaya kepemimpinan dan budaya organisasi terhadap produktivitas kerja pegawai dinas olah raga dan pemuda provinsi jawa barat. Jurnal Manajemen dan Bisnis, 9(17), 79-90.

Sugiyono. (2010). Memahami Penelitian Kualitatif. Bandung: Alfabeta. 